\title{
Environmental Impact Assessment and Management of Sewage Outfall Discharges using AUV'S
}

\author{
Patrícia Ramos ${ }^{1,2}$ and Mário V. Neves ${ }^{2}$ \\ 1 Institute of Accountancy and Administration of Porto \\ ${ }^{2}$ Faculty of Engineering of University of Porto \\ Portugal
}

\section{Introduction}

Wastewaters are often discharged into coastal waters through outfall diffusers that efficiently dilute effluent and usually restrict any environmental impact to a small area. Predicting this impact is however difficult because of the complexity of the hydrodynamic processes that mix the wastewater and also because of the variability in oceanic conditions. Despite great improvements in the understanding of these mixing processes over the years, since models are now available that can make reasonable predictions under steady-state conditions, there remain many aspects unknown and unpredictable. For this reason, much effort has been devoted recently to improving means to monitor and characterize sewage plumes under a variety of oceanographic conditions.

Traditional sampling techniques for underwater observation are generally expensive and do not offer a comprehensive coverage, specially as the requirements of oceanographic and environmental field studies, as those considered here, become more and more demanding. Clearly, in situ platforms, such as Autonomous Underwater Vehicles (AUVs), which are cost effective, mobile, and capable of capturing key phenomena adaptively, which is particularly interesting for oceanographic processes that vary widely and over several time and length scales, as is the case of sewage plumes, may improve environmental monitoring and predictive modeling for decision-making and management (Fletcher, 2001; Robinson et al., 1999; Yu et al., 1994).

In this chapter we describe how AUVs can be used with advantage for environmental impact assessment and management of sewage outfall discharges. The details and results of a monitoring campaign to a Portuguese outfall using an AUV are fully described.

\subsection{Isurus AUV}

Isurus is a REMUS class AUV, acquired to the Woods Hole Oceanographic Institution, MA, USA, in 1997 (Fig. 1). These vehicles are low cost, lightweight AUVs specially designed for coastal waters monitoring (Alt et al., 1994). The reduced weight and dimensions make them extremely easy to handle, requiring no special equipment for launching and recovery.

Isurus has a diameter of $20 \mathrm{~cm}$ and is about $1.5 \mathrm{~m}$ long, weighting about $35 \mathrm{~kg}$ in air. The maximum forward speed of the vehicle is $2 \mathrm{~m} / \mathrm{s}$, however the best energy efficiency is

Source: Underwater Vehicles, Book edited by: Alexander V. Inzartsev,

ISBN 978-953-7619-49-7, pp. 582, December 2008, I-Tech, Vienna, Austria 
achieved at about $1 \mathrm{~m} / \mathrm{s}$. At this velocity, the energy provided by a set of rechargeable lithium-ion batteries may last for over 20 hours.

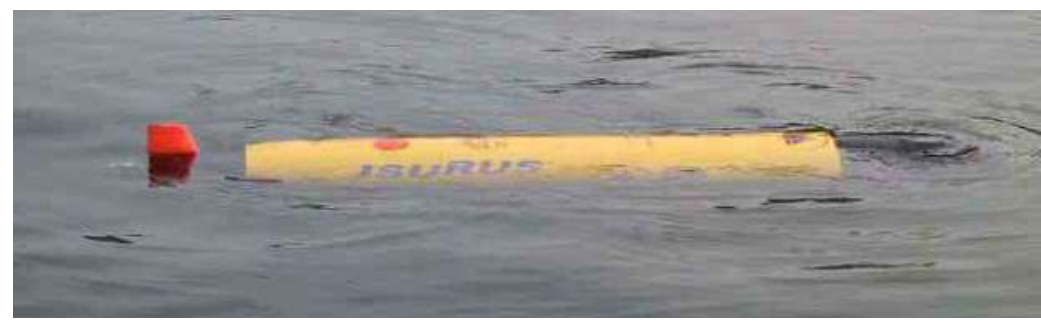

Fig. 1. Isurus Autonomous Underwater Vehicle.

Although small in size, this vehicle can accommodate a wide range of oceanographic sensors, according to mission objectives. For the field experiment described here two specific sensors were integrated: a conductivity, temperature, depth (CTD), OS200 model from Ocean Sensors, Inc., USA, and an altimeter to measure the height from the sea bottom, from Imagenex, Inc., Canada.

Since this type of vehicle operates without external control to perform the pre-defined mission transects, they have to be able to locate themselves in the field. The navigation system of Isurus AUV estimates in real time its position based on data provided from several devices and systems. The vertical coordinate is obtained from a pressure cell installed on the vehicle. To estimate the horizontal position, the navigation system fuses together dead reckoning data with absolute positioning data (Matos et al., 1999).

Typically, a mission starts with the vehicle programming, by editing a mission file in the laptop computer, with the tasks that need to be successively accomplished and the exact field location of the navigation transponders. After the final diagnostic, where the status of the various subsystems is checked, the mission file is transferred to the vehicle and the cable is disconnected. The vehicle is then launched in the water, from the coast or from a small boat. At this stage, the navigation and control programs are running and dictate the vehicle manoeuvres throughout the mission. The mission ends with the recovery of the vehicle in the expected final position. The connection with the laptop is then re-established and all the stored information is downloaded.

There are two data sets collected during a typical mission. The first set is related to the vehicle internal data, which are only analysed in the laboratory. These allow to evaluate the performance of various subsystems (navigation, control, power consumption, etc) and provide useful information for potential improvements. The other data set comprises all the information from the oceanographic sensors.

Usually, before processing, it is necessary to locate the collected data in time and space. While time location is obtained directly from the vehicle real-time clock, the spatial location is based on the vehicle position estimate provided by the navigation system (horizontal coordinates) and the depth cell (vertical coordinate).

If the spatial location of oceanographic data gathered with an AUV is known in a relatively precise manner, the same cannot be said for towyo platforms. In this case, even if the research vessel location is perfectly known, the natural instability of the cable, very difficult to control in a precise way specially with increased depth, can lead to positioning errors of the towed sensor package which can be critical for small scale phenomena observation. 


\subsection{S. Jacinto outfall}

A map of the study area is shown in Fig. 2. The S. Jacinto outfall is located off the Portuguese west coast near the Aveiro estuary. The total length of the outfall, including the diffuser, is $3378 \mathrm{~m}$ (the first $3135 \mathrm{~m}$ section having a diameter of $1600 \mathrm{~mm}$ and the last $243 \mathrm{~m}$ section having a diameter of $1200 \mathrm{~mm}$ ). The diffuser consisting of 72 ports alternating on each side, nominally $0.175 \mathrm{~m}$ in diameter, is $332.5 \mathrm{~m}$ long. Currently, only the last 20 of the 72 ports are working in a length of $98.2 \mathrm{~m}$. These are discharging upwards at an angle of $30^{\circ}$ to the horizontal axis, being the port height about $1.3 \mathrm{~m}$. The outfall has a true bearing direction of $290^{\circ}$ and is discharging at a varying depth approximately between 14 and $17 \mathrm{~m}$.

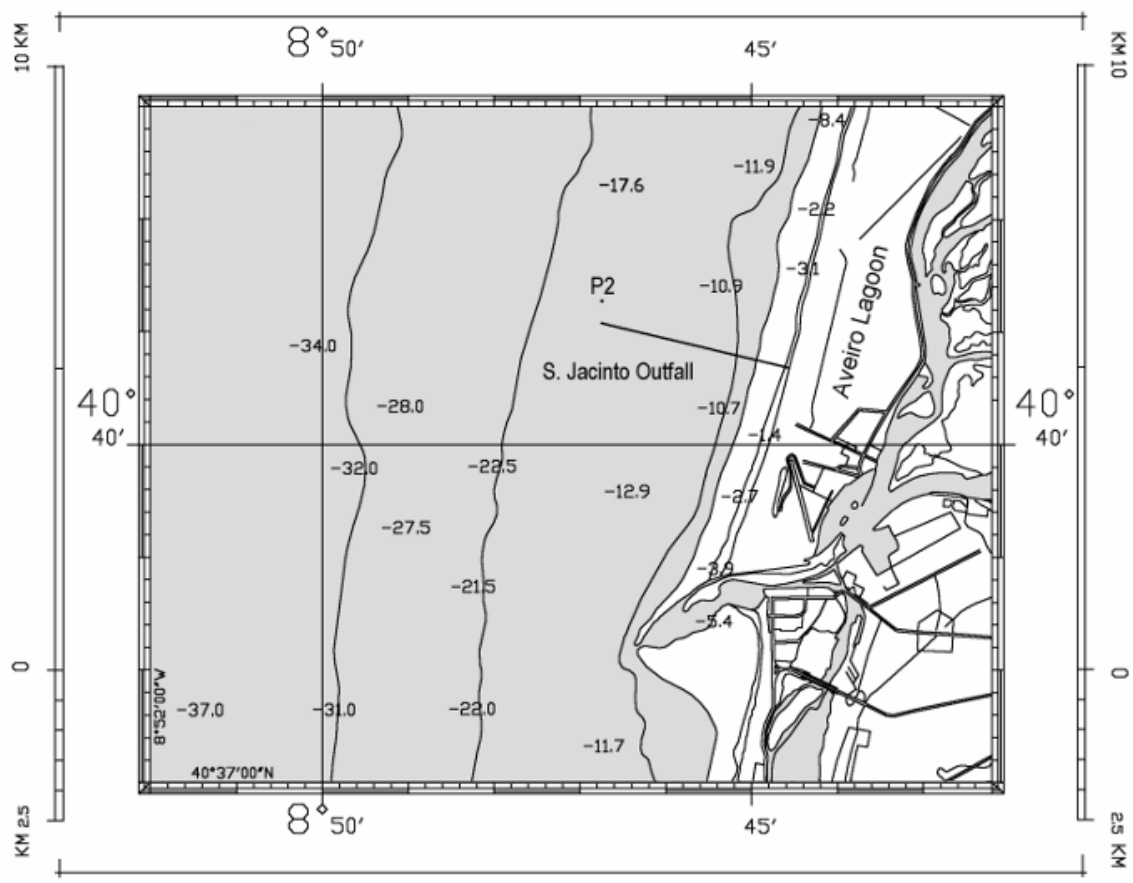

Fig. 2. Map of the study area.

The sea floor near the diffuser has a moderately sloping, sandy bottom with isobaths oriented parallel to the coastline. In that area the coastline itself runs at about a $200^{\circ}$ angle with respect to true north. Flow variation through the outfall in question is not typical of WWTPs since the effluent is mainly of industrial origin. Effluent flowrate ranges most frequently between $0.6-0.8 \mathrm{~m}^{3} / \mathrm{s}$.

During the campaign the discharge remained fairly constant, with an average flowrate of approximately $0.61 \mathrm{~m}^{3} / \mathrm{s}$.

The remainder of the chapter is outlined as follows. Section 2 describes the AUV near field monitoring mission to $S$. Jacinto outfall, focusing on the near-field transects and the ambient conditions. Data processing and results in terms of plume dispersion and dilution estimation are presented in Section 3. Finally, a brief summary of the main conclusions is presented in Section 4. 


\section{AUV monitoring mission}

One of the major problems related to the plume tracking studies is the sampling plan (Ramos, 2005). Usually, by observation of typical conditions in the vicinity of the outfall, namely density stratification and primary current directions that are most likely, investigators have some expectations of the effluent plume direction when it leaves the diffuser, its height of rise, thickness and even dilution.

However, oceanographic conditions seldom correspond exactly to those expected and values of density stratification, current speed and direction, etc will almost certainly be different in some degree from those predicted. When there is no flexibility in the plume tracking work plan, these changes in the expected oceanographic conditions can cause some problems: for example; (1) higher current speeds may result in an effluent plume that is more dispersed and that may extent beyond the survey area; (2) field transects not perpendicular to along-current direction may cause a distortion of plume characteristics such as spreading width, length of hydrodynamic mixing zone and minimum dilution, not valid to be compared with e.g. RSB model (Roberts et al.,1989) predictions which are to be observed in a vertical plane through the wastefield, perpendicular to current direction, at the end of the initial mixing region; (3) transects shape and resolution of the transects do not permit the end of the near field to be distinguished (Roberts et al., 2002); (4) the prescribed survey area may provide sampling out of the wastefield.

A race track design or any other type of complete sequential loops around the diffuser does not miss the plume, but, besides gathering useless data, is certainly not optimal for minimizing spatial and temporal aliasing effects.

Conducting previous exploratory transects to find gradients in the field that help to specify plume structure and behaviour may become a difficult task to natural tracer tracking.

Minimum dilutions reported in field studies may not always have been measured at the end of near field. In some cases, as admitted by the authors, measurements may have been obtained in a still rising plume, in which case dilution was incomplete. When the expected near field sampling actually took place beyond the hydrodynamic mixing zone, upper dilutions were certainly considered.

\subsection{Mission transects}

Within the near field, plumes are energetically turbulent with wide variations in instantaneous measurements (Roberts, 1996). Sampling within this area is therefore problematic as results may fluctuate widely and be difficult to interpret. One of the main goals of this work was to develop a reliable in situ method to monitor pollutants discharged in the environment with increased temporal and spatial resolution, making use of an AUV. In order to reduce the uncertainty about plume location and concentrate the monitoring mission only in the hydrodynamic mixing zone, outputs of a near field prediction model, based on effective real time in situ measurements of current speed and direction and density stratification, were opportunistically used to specify in real time the mission transects (Ramos, 2005).

The near field model used was RSB (Roberts et al., 1989). The RSB model, based on the experimental work on multiport diffusers of Roberts et al. (1989) using dimensional analysis and length scale arguments, incorporates the most important hydrodynamic aspects of ocean outfalls. These include, the effects of arbitrary current speed and direction (including parallel currents), stratification, port spacing, source momentum flux, discharges from both 
sides of the diffuser and the resulting merging of the plumes from both sides, reentrainment and additional mixing in the spreading layer, direct plume impingement in parallel currents, and lateral gravitational spreading.

The model has been validated against data: (1) from a field tracer and laboratory experiments to the San Francisco outfall (Roberts \& Wilson, 1990), (2) from field tests to Whites Point, Los Angeles outfall (Washburn et al., 1992) and Sand Island, Hawaii outfall (Petrenko et al., 1998), and recently (3) from field tracer experiments to Boston outfall (Roberts et al., 2002).

The RSB outputs, including length of hydrodynamic mixing zone, spreading width at the end of the near field, maximum rise height and thickness, in conjunction with current direction, were used to define the sampling transects.

To guarantee the plume observation at the end of near field, the longitudinal distance was actually considered somewhat greater than the initial mixing zone length. The maximum downstream normalized distance used by Roberts et al. (1989) in its laboratory experiments was, in fact, the survey length considered. A minimum safe distance to the outfall was also guaranteed to avoid jets turbulence affect the vehicle navigation. The minimum downstream normalized distance used by Roberts et al. (1989) in its laboratory experiments was used as reference. The wastefield width was increased in $20 \%$ to take into account experimental errors, as suggested by Roberts et al. (1989). A minimum distance of $4 \mathrm{~m}$ from the sea bed (due to safety navigation requirements), and a minimum distance of $2 \mathrm{~m}$ from the surface (due to wave motions interference with the vehicle navigation) was also considered. Eliminating unnecessary measurements, this adaptive sampling approach enables to increase the horizontal and vertical resolutions, that are specially critical to natural tracer tracking in environments with large gradients in background values of the natural tracer.

Yo-yo shaped transects were not particularly useful in this case. With a maximum dive angle of $10^{\circ}$, the vehicle would perform minimum cycles of 159-193 m in yo-yos of 14-17 m amplitude, with a horizontal resolution between $79-96 \mathrm{~m}$ at the middle of the water column. If the wastefield width at the end of near field is about 1.5 times the diffuser length (Roberts et al. 1989), i.e. $147 \mathrm{~m}$, the AUV would perform not more than 2 yo-yos in each transect, missing lot of data.

So, horizontal transects at different depths with a minimum vertical spacing of $2 \mathrm{~m}$ and a minimum spacing of $20 \mathrm{~m}$ between horizontal parallel transects, due to the natural navigation variability in depth of Isurus AUV, seemed to be a right choice for these specific study conditions.

Tracks perpendicular to current direction, instead of parallel, are preferred to minimize temporal aliasing between samples at the same cross section. Cross sections at the end of near field can be comparable to RSB model predictions. Tracks parallel to down current direction are preferred to observe how dilution varies with distance.

To be able to compare field observations with model predictions, density vertical profiles should be collected outside the dispersion area (unaffected by the plume salinity). Those profiles are necessary to run the models.

Two applications were developed to implement easily in the field the sampling strategy adopted. Sea Outfall Monitoring Campaign GUI is used for the automatic specification of the inspection area, and Isurus Mission GUI is used for the automatic definition of the AUV mission file (see their layouts during S. Jacinto outfall campaign in Fig. 3 and Fig. 4). 


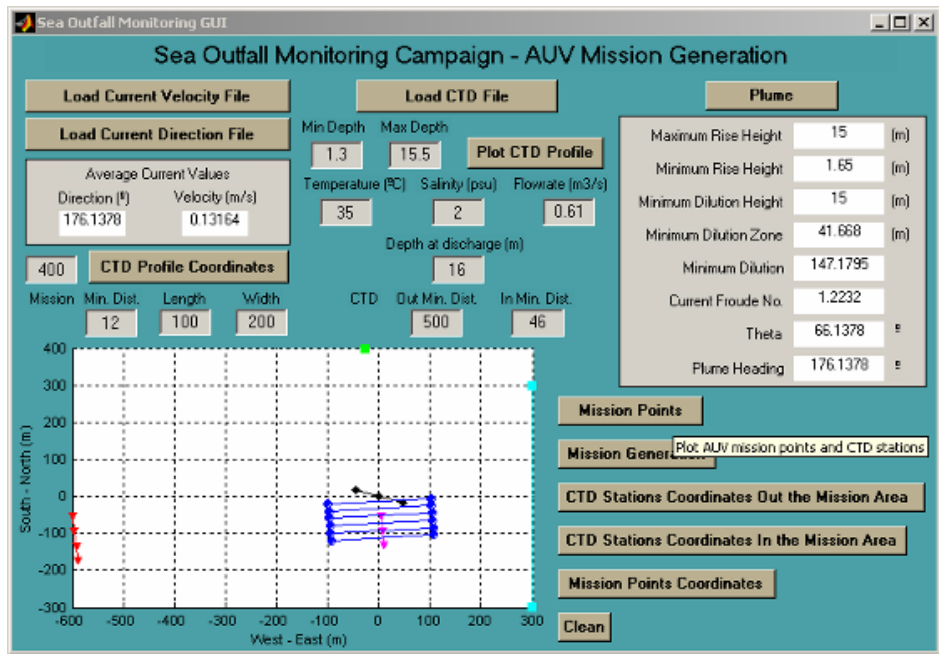

Fig. 3. Sea Outfall Monitoring Campaign GUI layout during for S. Jacinto outfall monitoring campaign.

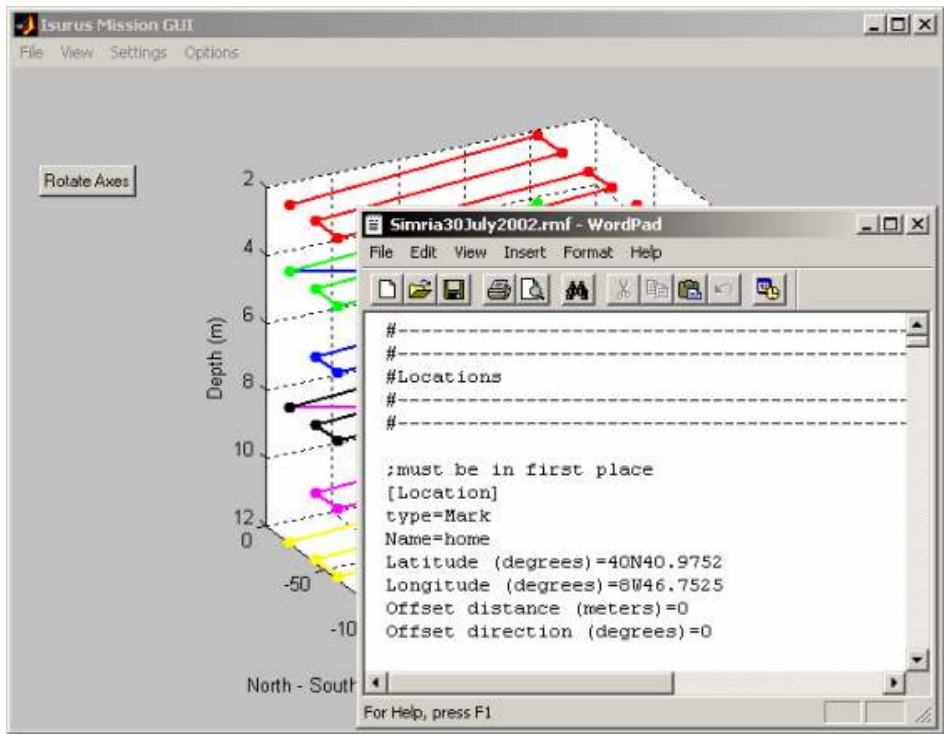

Fig. 4. Isurus Mission GUI layout during for S. Jacinto outfall monitoring campaign.

According to RSB model predictions, obtained in real time during S. Jacinto outfall monitoring campaign, the plume was spreading at the surface, detached from the bottom and forming a two-layer flow. At the end of the near field $42 \mathrm{~m}$ downstream from the diffuser, the predicted wastefield width was about $177 \mathrm{~m}$.

The AUV monitoring mission took about 112 minutes, starting approximately at 14:00 GMT. A rectangular area of $200 \mathrm{~m} \times 100 \mathrm{~m}$ starting $20 \mathrm{~m}$ downstream from the middle point of the diffuser was covered (see the vehicle position estimate in Fig. 5). 
As predicted, the vehicle performed six horizontal trajectories at 2, 4, 6, 8, 10, and $12 \mathrm{~m}$ depth. In each horizontal trajectory, the vehicle described six parallel transects perpendicular to the water current direction, of $200 \mathrm{~m}$ length and spacings of $20 \mathrm{~m}$ (labelled as section 1-6 in Fig. 5).

In performing horizontal trajectories, vertical oscillations of the AUV were less than $0.5 \mathrm{~m}$. During the mission the vehicle transited at a fairly constant velocity of $1 \mathrm{~m} / \mathrm{s}$.

CTD data were recorded at a rate of $2.4 \mathrm{~Hz}$, so horizontal resolution was about $0.4 \mathrm{~m}$ (horizontal resolution is defined here as the approximate distance between consecutive points that are sampled at the same depth, i.e., in the same layer). Vertical resolution varied along the mission due to the influence on the vehicle navigation of natural currents but was almost always between 1-2 m (vertical resolution is defined as the vertical distance between points in the water column that are sampled approximately at the same $(X, Y)$ location but at consecutive depths, i.e., on successive layers).

Comparing to other field studies (Washburn et al., 1992; Wu et al., 1994; Petrenko et al., 1998) this resolution corresponds to a huge improvement in plume tracking surveys.

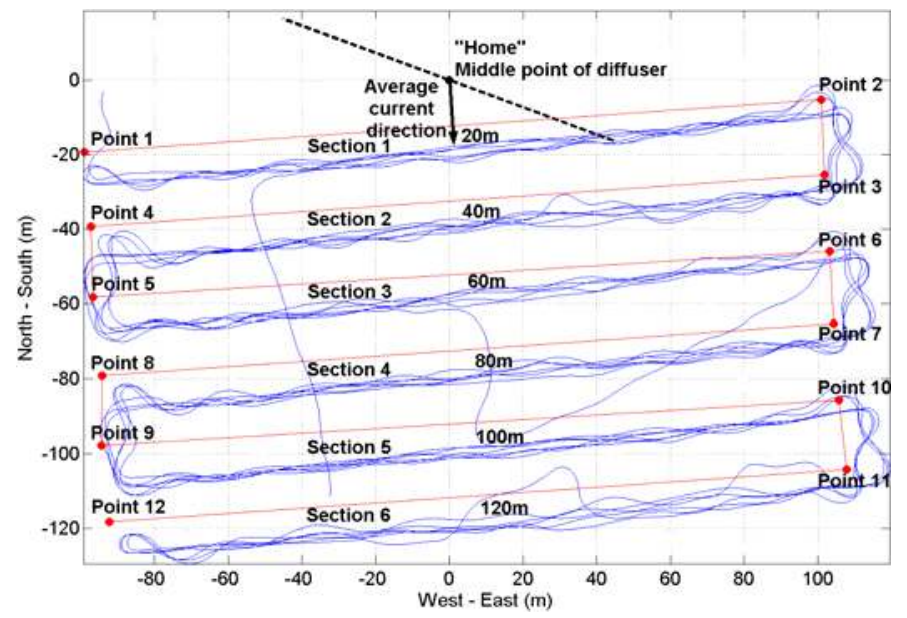

Fig. 5. Plan view of the AUV position estimate during the plume tracking survey downstream from the outfall diffuser.

Although the position estimate, provided by the navigation system, is accurate enough for the guidance and control of the AUV, it is not well suited for spatially locating the data collected. In fact, the discrete nature of the correction mechanism used in real time gives rise to discontinuities in the evolution of the estimate, which is a major drawback for spatially locating the collected data (Matos et al., 2003).

An algorithm that processes the data collected by the vehicle navigation system during the execution of a mission and produces an estimate of the trajectory described by the vehicle more suited for spatially locating the oceanographic data gathered was applied (see the details in Matos et al. (2003)). The final result is shown in Fig. 5.

Little deviation from the line transects specified (in red) is observed, with an exception to the trajectory at $4 \mathrm{~m}$ depth, in sections 3 and 6 , where the navigation system could not correct the vehicle position estimate, because no valuable information was being received at that time from the transponders. 
A larger distance of $\sim 20 \mathrm{~m}$ from the middle point of the diffuser to the middle point of section 1, instead of the $12 \mathrm{~m}$ considered in the mission specification, was observed. This offset of about $8 \mathrm{~m}$ between the predicted and performed trajectories was not result of a poor performance of the navigation algorithm, but a direct consequence of the relative strong water current to the south during the mission. In fact, the heading reference generated by the vehicle guidance system does not integrate the off track error, giving rise to large off track errors when there are large water currents perpendicular to the desired trajectory (Matos et al. 2003).

During the vehicle deployment process, a drift from the "home" position, where it was supposed to be launched, occurred, so a correction to the expected trajectory from Point 1 to Point 2 was efficiently performed by the navigation system at the beginning of the mission in the trajectory at $2 \mathrm{~m}$ depth.

\subsection{Field conditions summary}

The data on the currents field were obtained from a downward-looking Acoustic Doppler Current Profiler (ADCP) (Workhorse Sentinel $600 \mathrm{kHz}$ model, RD Instruments, Inc.) deployed through a small boat for a few minutes before the start of the AUV mission.

One vertical profile of horizontal current components was provided with measurements at $0.5 \mathrm{~m}$ vertical increments between 1.55 and $14.05 \mathrm{~m}$ depth.

The motion of the surface waters, down to a depth of about $8.55 \mathrm{~m}$, was generally to the South; the deeper currents moved generally between SE-SSE, with average direction $176.14^{\circ}$ over the whole water column. The predominant current direction was then to the south, almost perpendicular to the diffuser axis. Current speeds were generally between $0.1-0.25 \mathrm{~m} / \mathrm{s}$ over the whole water column, with the average being about $0.132 \mathrm{~m} / \mathrm{s}$.

Information on density stratification at the same location was also obtained with an OCEANSEVEN 316 multi-sensor (manufactured by IDRONAUT-Italy) to run RSB model.

A similar profile was acquired by Isurus AUV close to Point 1 during its ascending trajectory from $12 \mathrm{~m}$ depth to the surface, at the end of the mission. Fig. 6 shows vertical temperature, salinity and density measurements averaged into 2-s bins.

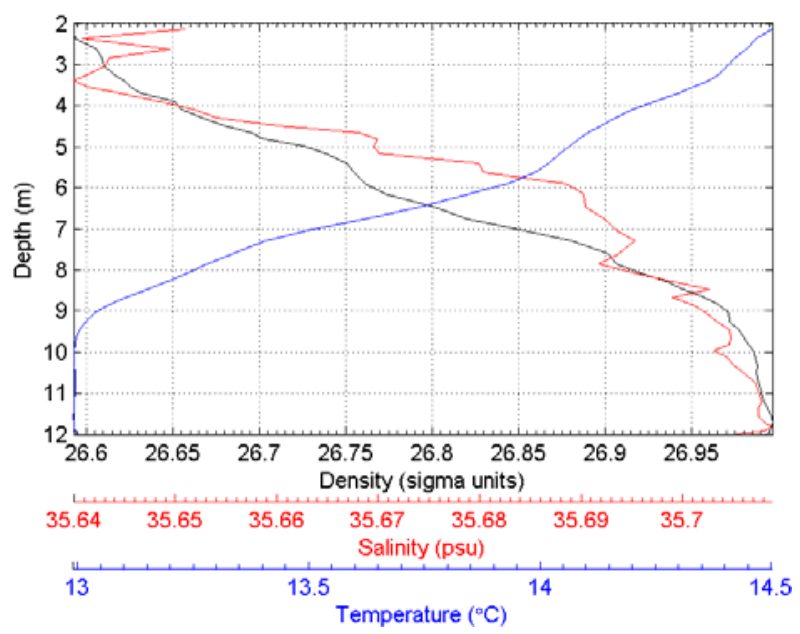

Fig. 6. Vertical STD profiles measured by Isurus near the diffuser. 
The water column was weakly stratified due to both low temperature and salinity variations in the vicinity of the diffuser.

The temperature difference between the surface and the bottom was about $1.5^{\circ} \mathrm{C}$, with most of the difference occurring in a thermocline that extended from $\sim 2 \mathrm{~m}$ to $10 \mathrm{~m}$.

The salinity profile showed some variability extending over the whole water column, with the difference between the bottom and the surface being about $0.07 \mathrm{psu}$.

The total difference in density over the water column was about $0.48 \sigma$-units, with the change with depth being approximately linear.

The buoyancy frequency from the discharge depth to the surface was then

$$
N=\sqrt{-\frac{g}{\rho_{a}} \frac{d \rho}{d z}}=0.02 s^{-1},
$$

where $g=9.8$ is the acceleration due to gravity, $\rho_{a}=1026.99$ is the seawater density at the port depth, and $d \rho / d z=0.48 / 15$ is the vertical density gradient. The discharge depth during the AUV mission was about $15 \mathrm{~m}$. The Froude number $F$, based upon the current speed and one of the most important parameters governing the dynamics of the diffuser flow in the near-field, was equal to (Roberts et al., 1989)

$$
F=\frac{u^{3}}{b}=1.18
$$

where $u=0.132$ is the current speed, and $b$ is the buoyancy flux per unit length of the diffuser equal to $g\left(\Delta \rho / \rho_{a}\right) Q / L$, where $\Delta \rho=31.47$ is the density difference between the seawater and wastewater at the port level, $Q=0.61$ the volume flow rate of wastewater, and $L=98.2$ the diffuser length.

\section{Results and discussion}

\subsection{Plume spatial characterization}

\subsubsection{Data processing}

In order to map effectively the dispersion of the effluent using the AUV data, three main steps were followed.

In the first step, after a global analysis of the collected data (where, for example, errors due to sensor malfunctions were detected), an estimate of the appropriate trajectory described by the vehicle for the spatial location of the collected oceanographic data was produced.

The uncertainty of the horizontal position estimate was less than $5 \mathrm{~m}$. The uncertainty of the vertical position estimate was even less, due to the high precision complementary measurements of the eco-sounder. Then CTD and navigation data were merged onto a common time base using linear interpolation. Positioning data were rotated about $-3.86^{\circ}$ so that North-South/East-West lines were aligned with $x-y$ axis.

In the second step, using the polynomials developed by Millero et al. (1980), in situ conductivity, temperature and pressure were used to compute salinity. Then, density was estimated by using this computed salinity and the measured temperature and pressure. Finally, the last step was to plot the desired variables onto $x-y, x-z$, and $y-z \$$ grids using the Least Squares Collocation Method (LSCM) technique (see details in Zhang et al. 
(2001) and Ramos (2005)). The LSCM has been used for numerous applications, namely the numerical solution of differential equations such as the Navier-Stokes equations and hyperbolic problems, including the shallow water equations, to interpolate gravity at any given location using only measurements at some discrete locations, etc.

To apply Least-Squares Collocation Method, we first chose a finite set of $N=396$ collocation points $\left\{X_{j}\right\}_{j=1, \ldots, 396}=\{\{-90: 20: 110\},\{-120: 20:-20\},\{2: 2: 12\}\} \quad$ in the measurements domain $\Omega=[-98,118] \times[-125,3] \times[1,13]$.

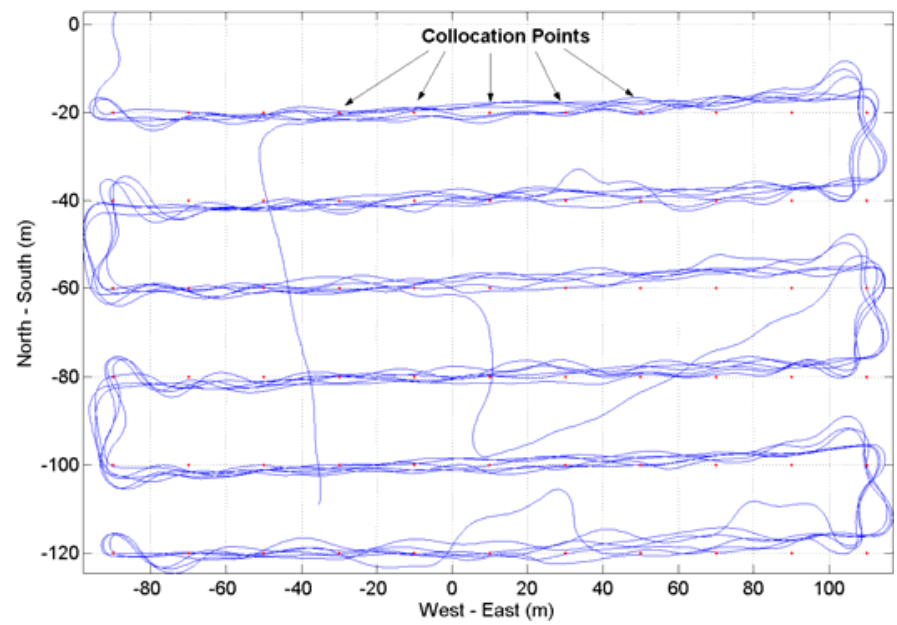

Fig. 7. Plan view of the AUV plume tracking survey and collocation points.

Then an approximation of the desired variable (in this case, salinity, temperature and density, denoted by P) between measured and collocation points in the form was assumed

$$
P_{i} \approx \sum_{j=1}^{N} W_{i j} \widehat{P}_{j}, \quad i=1, \ldots n \Leftrightarrow P=W \widehat{P}
$$

where $P_{i}$ is the measurement at point $X_{i}$, with $n=16075$ observations, $\hat{P}_{j}$ represents the approximated measurement at collocation point $X_{j}$, and $W_{i j}$ is an elementary function usually built in such a way that it takes a certain value if $X_{i}$ is in the influence domain of point $X_{j}$, the region $\Omega_{j}$, and vanishes outside the region $\Omega_{j}$ surrounding the point $X_{j} . W$ is a $n$ by $N$ matrix $(n>N)$ where the column vector $j$ represents the magnitudes of the approximated measurement of collocation point $X_{j}$ with respect to each observation $i$, and where the row vector $i$ represents the magnitudes of the approximated measurements of each collocation point $X_{j}$ with respect to observation point $X_{i}$.

The choice for the elementary function $W_{i j}$ was the following raised cosine function

$$
W_{i j}(d)=\left\{\begin{array}{cl}
\frac{1}{2}+\frac{1}{2} \cos (\pi d), & 0 \leq d<1 \\
0, & d \geq 1
\end{array}\right.
$$

where $d$ is a normalized distance given by 


$$
d\left(X_{i}, X_{j}\right)=\left\|X_{i}-X_{j}\right\|_{n r m}=\left[\left(\frac{\left|x_{i}-x_{j}\right|}{\Delta x}\right)^{n r m}+\left(\frac{\left|y_{i}-y_{j}\right|}{\Delta y}\right)^{n r m}+\left(\frac{\left|z_{i}-z_{j}\right|}{\Delta z}\right)^{n r m}\right]^{\frac{1}{n r m}}
$$

being $n r m=2.45, X_{i}=\left(x_{i}, y_{i}, z_{i}\right), X_{j}=\left(x_{j}, y_{j}, z_{j}\right)$, and $\Delta x=20, \Delta y=20$ and $\Delta z=2$ the cell grid distances, respectively, in $x, y$ and $z$ axis, between consecutive collocation points.

If $X_{i}$ is in the influence domain of point $X_{j}$, the value $W_{i j}$ is as large as less distanced are the points $X_{i}$ and $X_{j}$, being a unit value when $X_{j}=X_{i}$ (and null for all the other collocation points).

Since the magnitudes are constants, Equation (3) is an overdetermined linear system of equations ( $n$ equations with $N$ unknowns) that can be solved using least squares method, by one of the several mathematical packages such as Matlab, the one used in this case.

The least squares functional is defined by summing the squares of the residuals evaluated for each point $X_{i}$

$$
J=\sum_{i=1}^{n}\left[P_{i}-\sum_{j=1}^{N} W_{i j} \hat{P}_{j}\right]^{2}=(P-W \hat{P})^{T}(P-W \hat{P}) .
$$

Minimization of Equation (6) with respect to $\widehat{P}$ leads to

$$
\left(W^{T} W\right) \hat{P}=W^{T} P
$$

where $W^{T}$ is the transpose of matrix $W$. Solving the resulting system (of $N$ equations with $N$ unknowns) for $\hat{P}$ we obtain

$$
\widehat{P}=\left(W^{T} W\right)^{-1} W^{T} P .
$$

An important advantage of this method is the sparsity of the matrix $W$. Since $W$ has a high percentage of zero-valued elements, using a sparse matrix data only the nonzero elements and their indices are stored, reducing significantly the amount of memory for storage, and making the matrix inversion calculation process more efficient. Only a few seconds were necessary for the matrix inversion process, being $W$ a 16075 by 396 matrix. Notice that $d$ was not defined exactly as Euclidean distance, i.e. $L_{2}$ norm, but a $L_{2.45}$ norm. The explanation for this is illustrated in Fig. 8: plots (a) and (b) show the behaviour of function $W$ for a $1 \mathrm{D}$ measurement domain $\Omega=[0,4]$, and collocation points $\left\{X_{j}\right\}_{j=1,2,3}=\{1,2,3\}$ with $\Omega_{1}=[0,2], \Omega_{2}=[1,3]$ and $\Omega_{3}=[2,4]$; plots (c), (d), and (e) show the behaviour of function $W$ for a $2 \mathrm{D}$ measurement domain $\Omega=[0,3] \times[0,3]$, and collocation points $\left\{X_{j}\right\}_{j=1,2,3,4}=\{(1,1),(2,1),(1,2),(2,2)\} \quad$ with $\Omega_{1}=[0,2] \times[0,2]$, $\Omega_{2}=[1,3] \times[0,2], \Omega_{3}=[0,2] \times[1,3]$, and $\Omega_{4}=[1,3] \times[1,3]$ using $L_{2}$ norm, and plots $(\mathrm{f}),(\mathrm{g})$, and $(h)$ are the same as before except using $L_{2.45}$ norm.

As can be seen from plot (b), in the 1D measurement domain case, the sum of magnitudes of the approximated measurements of each collocation point $X_{j}$ with respect to a observation 
point $X_{i}$, with $d=\left|x_{i}-x_{j}\right|$ in the influence domain of point $X_{j}$ is, as expected, a unit value, except in the boundaries of course. In the 2D measurement domain case, as can be seen from plot (d) and (e), the sum of magnitudes of the approximated measurements of each collocation point $X_{j}$ with respect to a observation point $X_{i}$, with $d=\sqrt{\left|x_{i}-x_{j}\right|^{2}+\left|y_{i}-y_{j}\right|^{2}}$, the Euclidean distance, in the influence domain of point $X_{j}$, is not as should, a unit value, except of course in the boundaries.
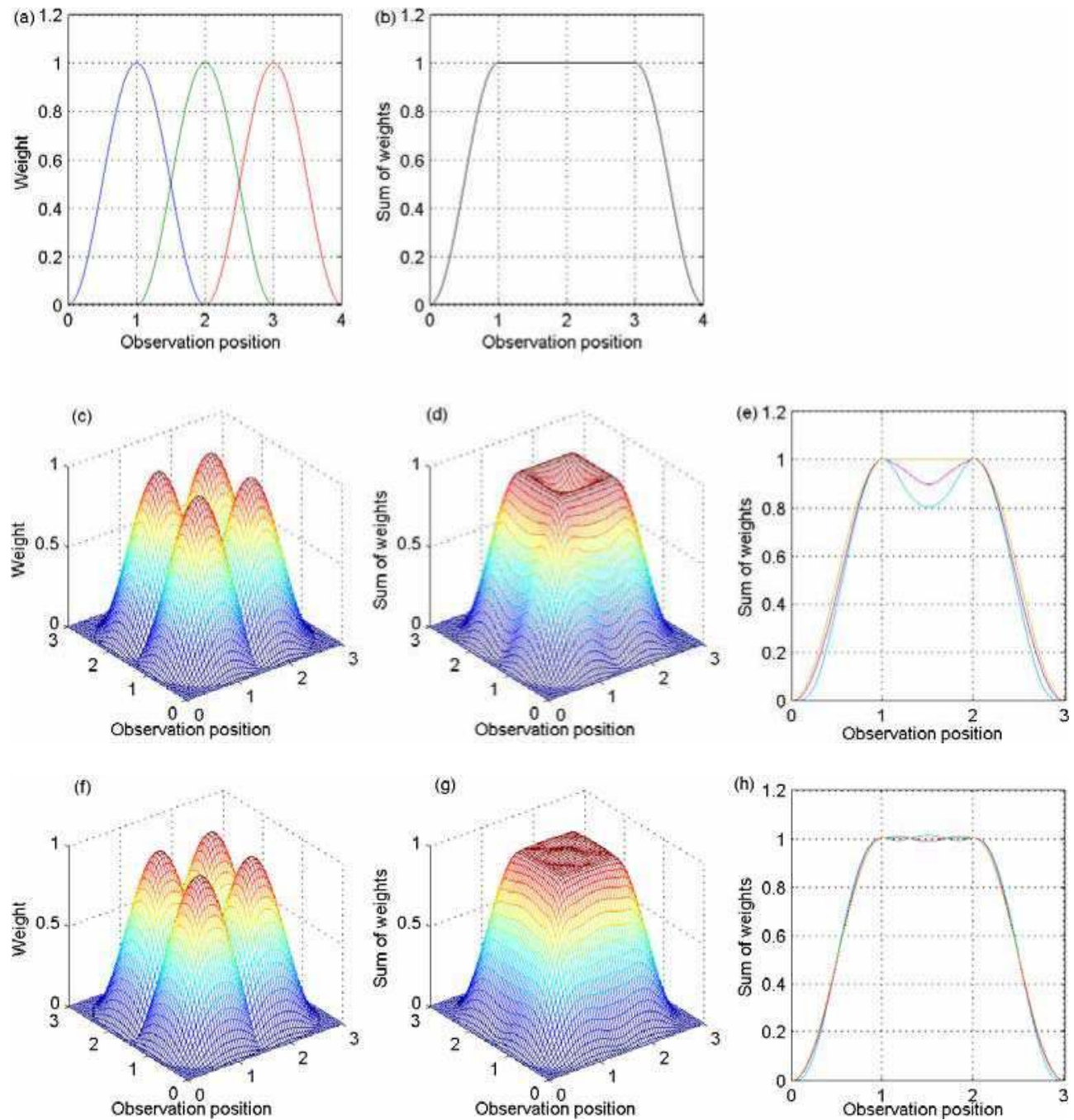

Fig. 8. Behaviour of weight function $W$ for 1D and 2D measurement domains, using norm $L_{2}$ and $L_{2.45}$ in $2 \mathrm{D}$ case. 
This problem is partially eliminated if a norm $L_{2.45}$ is used, as show plots (g) and (h). This value was empirically adjusted so that the sum of magnitudes of the measurements of each collocation point be approximated a unit value. Cross sections for the $3 \mathrm{D}$ measurements domain case (not shown) were performed and the results are similar to the $2 \mathrm{D}$ case previously presented.

A "less visited collocation point" $X_{j}$ was defined as one whose sum of magnitudes (sum of elements of column vector $j$ ) was less then the difference between the mean value of the all sums of magnitudes (SumMag) and three times the standard deviation of these sums

$$
\text { lessvisit }_{j}=\sum_{i=1}^{n} W_{i j}<(\text { mean }(\text { SumMag })-3 \times \operatorname{std}(\text { SumMag })) .
$$

To increase information on the desired variable in the vicinity of less visited collocation points $X_{j}$, a cell grid size update was performed

$$
[\Delta x \Delta y \Delta z]_{j}=\text { cell_growth } \times[\Delta x \Delta y \Delta z]
$$

where cell_growth $=5$.

Finally, a finer meshgrid of the form $[\Delta x \Delta y \Delta z]=\left[\begin{array}{lll}2 & 2 & 0.2\end{array}\right]$ was considered for the surface visualization generation. The desired variable on the $M$ visualization points was calculated as follows

$$
\widetilde{P}_{k}=\sum_{j=1}^{N} \widetilde{W}_{k j} \widehat{P}_{j}+\operatorname{mean}(P), \quad k=1, \ldots, M
$$

were the weights matrix $\widetilde{W}_{k j}$ was evaluated in the same manner as (4). To improve the method efficiency, the least squares solution (8) was either computed as follows

$$
\widehat{P}=\left(W^{T} W\right)^{-1} W T(P-\operatorname{mean}(P))
$$

so the mean value has to be added in (11). Several interpolation methods such as Nearest Neighbor, Bilinear, and Bicubic were first applied to the measured data but with no successful results. The LSCM was then considered since it is specially attractive for problems posed on irregularity shaped domains, which is the case here. Giving the intermittence of the phenomena in observation, using "local" functions instead of using elementary functions which cover the all measurements domain (e.g., Fourier Series), no influence is assumed between widely estimated measurements of the desired variable.

\subsubsection{Results}

As in other field studies (Washburn et al., 1992; Petrenko et al. 1998; Jones et al. 2001), salinity was found to be more useful than either temperature or density in delineating and observing the plume structure. The LSCM results for the salinity parameter are presented in Fig. 9. From those figures, plotted with the same color scale, it is possible to identify unambiguously the effluent plume and to observe its dispersion downstream in the NorthSouth direction. It appears as a region of lower salinity compared to surrounding ocean 

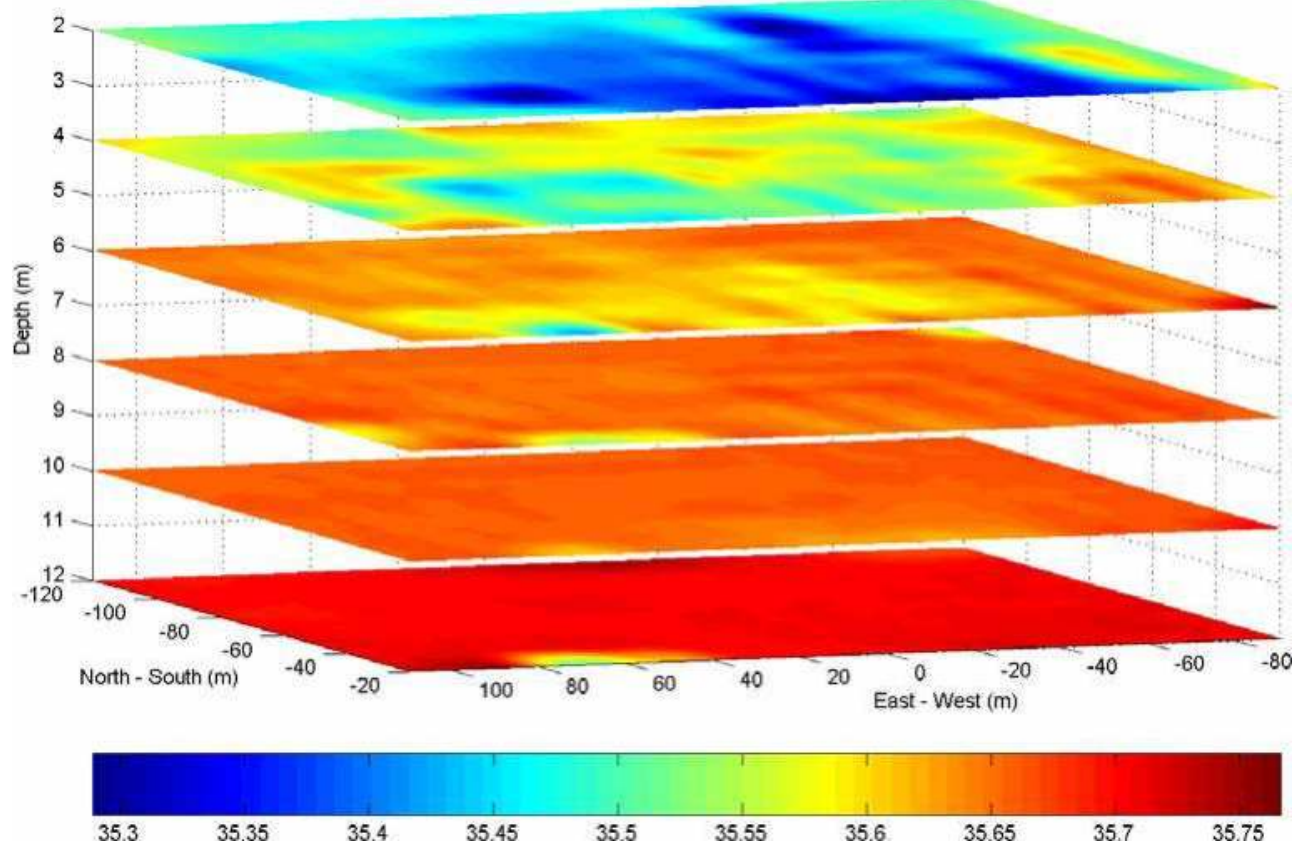

(a)
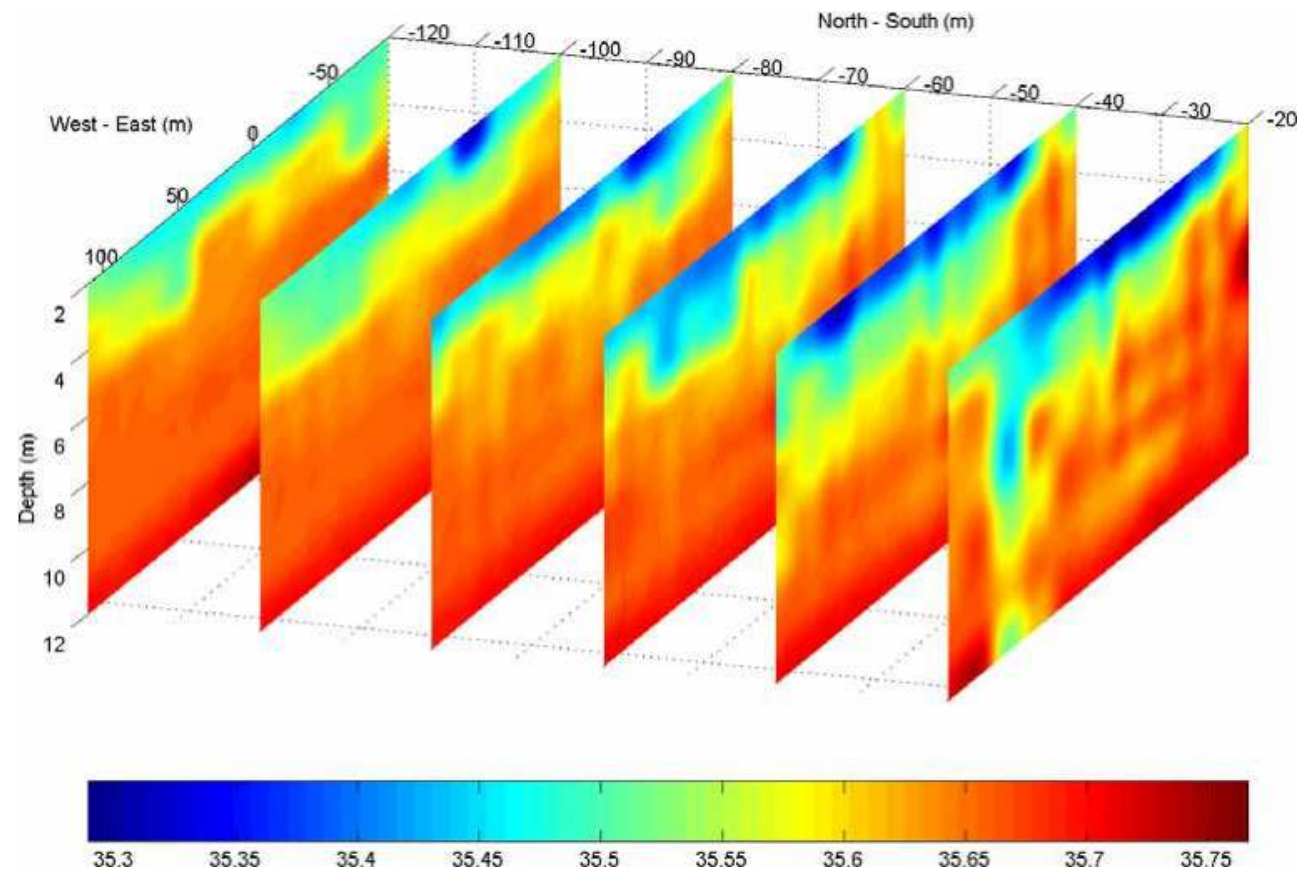

(b) 

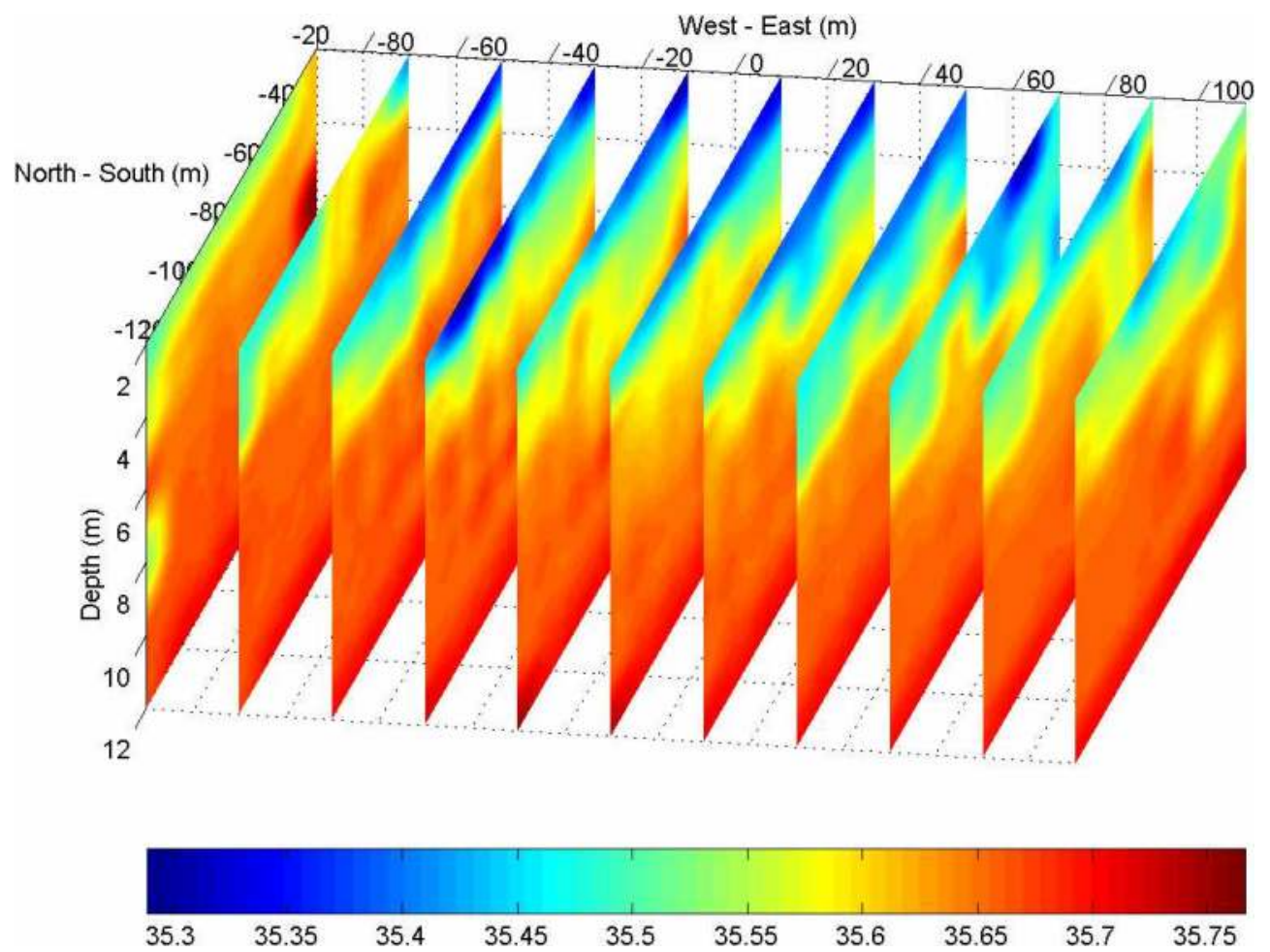

(c)

Fig. 9. (a) Salinity transversal sections (psu units) at 20, 40, 60, 80, 100 and $120 \mathrm{~m}$ downstream from the middle point of the diffuser; (b) Salinity horizontal sections (psu units) at 2, 4, 6, 8, 10, and $12 \mathrm{~m}$ depth; Salinity longitudinal sections (psu units) from $-20 \mathrm{~m}$ West to 100 m East.

waters at the same depth, rising to the water surface due to the relatively weak stratification, low currents and shallow waters.

In the $20 \mathrm{~m}$ transversal section and on the several horizontal sections in the region close to the diffuser it is possible to observe the plume rising from near the bottom to the surface, in accordance with Fig. 5 (see that the East end of the diffuser is over the first transect). South from the diffuser, downstream, there is also evidence of the presence of the effluent plume at the surface, with salinity decreasing to the edges.

Major differences in salinity between the plume and surrounding waters at the surface was observed to be about 0.4 psu in the first two sections, decreasing to about $0.15 \mathrm{psu}$ in the third and fourth sections, and being less than $0.1 \mathrm{psu}$ in the fifth section, finally being almost equal to that of background waters at $120 \mathrm{~m}$ distance from the diffuser.

Salinity anomalies of the same order were found by Washburn et al. (1992) and Petrenko et al. (1998). Vertical profiles of salinity collected by Petrenko et al. (1998) at the center and over the western end of the diffuser, where the highest effluent concentrations were found, indicated differences of $0.2 \mathrm{psu}$. Typical salinity anomalies in the plume of the order of 0.1 psu were observed by Washburn et al. (1992). 
The effluent plume was detected from close to the surface (at minimum depths around $1.5 \mathrm{~m}$ ) to nearly $8 \mathrm{~m}$ depth from the first to the fourth section with clearly decreasing thickness downstream. A sharp difference in salinity at the effluent plume lateral edges is clearly visible.

The form of the wastefield spreading (almost centered in the survey area) indicates that the sampling strategy designed was very successful, even for a surfacing plume. A surfacing plume, several times more diluted than a submerged plume, surrounded by low salinity surface waters, with its own weak signals, could be further blurred by the background signals (Petrenko et al., 1998).

The plume exhibits a considerably more complex structure than the compact shape of the classical picture of the buoyant plume but is not so patchy as in previous studies, perhaps because of improvements in horizontal and vertical resolution (Faisst et al., 1990; Petrenko et al., 1998; Jones et al., 2001; Carvalho et al., 2002).

Roberts et al. (1989) laboratory experiments on multiport diffusers in density-stratified perpendicular crossflows show that at low current speeds $(F \approx 0.1)$ the flow has the normal plume-like pattern with the plume bent downstream. At higher current speeds $(F \approx 10)$ the plume cannot entrain all of the incoming flow while maintaining the free plume pattern and the base of the wastefield stays at the nozzle level. This is known as the forced entrainment regime, which occurs when the Froude number $F$ defined above exceeds a value which lies somewhere between 1 and 10. The rise height and thickness of the wastefield decrease with increasing current speed in the forced entrainment regime. Our in situ observations and measured value of the Froude number seem to be in agreement with these experiments. The observations indicate that the plume is being swept downstream and not attached to the lower boundary, a regime that lies between the two mentioned, in agreement with the behavior expected for a measured Froude number $F=1.18$.

\subsection{Dilution estimation}

Dilution was estimated empirically using temperature and salinity and their representation on a TS - diagram, with initial mixing lines between sewage effluent and receiving waters. Details of this method may be found in Washburn et al. (1992) and Petrenko et al. (1998).

When sewage effluent (with temperature $T_{e}$ and salinity $S_{e}$ is discharged, it starts mixing with receiving waters (with temperature $T_{a}$ and salinity $S_{a}$ ) at the port level. The temperature and salinity of the mixed water mass, respectively $T_{m}$ and $S_{m}$, correspond to a point of the mixing line connecting the effluent and the ambient TS-points. The characteristics $T_{m}$ and $S_{m}$ vary according to the dilution factor between the effluent and the receiving waters. For a given dilution $S, T_{m}$ and $S_{m}$ are equal to (Fischer et al. 1979)

$$
\left\{\begin{array}{l}
T_{m}=T_{a}+\frac{T_{e}-T_{a}}{S} \\
S_{m}=S_{a}+\frac{S_{e}-S_{a}}{S}
\end{array}\right.
$$

As previously mentioned, mixing in the near-field occurs during the plume rise over the outfall diffuser. The observations indicate that some of this initial mixing occurs between 15 and $11 \mathrm{~m}$ depth. Two ambient TS - points from those two depths were then considered to account for variability in background conditions. 
Fig. 10 shows temperature and salinity measured at Section 1 plotted in a TS-diagram. TS - points measured at the same depth were plotted with the same color: red, blue and black correspond respectively to 12, 10 and 8 m depth. The isopycnals (lines of constant density) are labelled in sigma units.

Simultaneously, initial mixing lines are drawn between the effluent TS - point (not shown) $T_{e}=35^{\circ}$ and $S_{e}=2 \mathrm{psu}$, and the two ambient $T S$ - points $\left(T_{a}\right.$ and $\left.S_{a}\right)$ at 15 and $11 \mathrm{~m}$ depth. TS - points of these two mixing lines with equal dilutions delimit intervals of initial dilutions. TS - points $\left(T_{m}\right.$ and $\left.S_{m}\right)$ for dilution factors of 30, 35, 40, 45, 50, 55, 60, 70, 80, 90, $100,120,150,200,300$ and 400 are indicated.

Dilution can be estimated empirically based on the fact that TS - points in the plume are single end-members of the mixing between the effluent and the receiving waters. The TS - points in the plume with the lowest dilution falling into an initial dilution zone establish the minimum initial dilution.

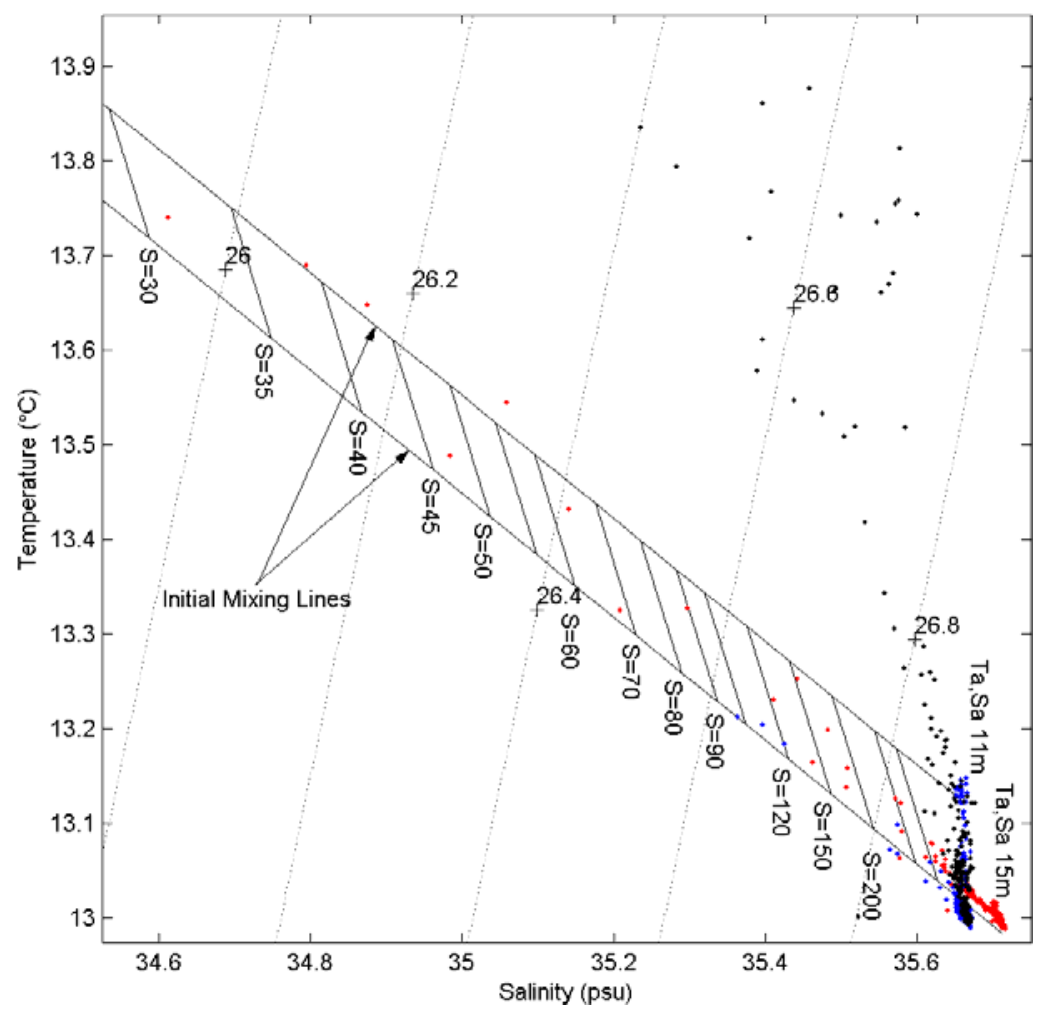

Fig. 10. Temperature-Salinity (TS -) diagram of data from Section 1.

The TS - points in the plume located off the initial mixing lines have already started to mix with waters above $11 \mathrm{~m}$ depth. According to these results, effluent dilutions were then at least 30:1. This value is probably a lower bound of the dilution since, in reality, mixing continued to occur up to surface. However, with this method no further dilution can be inferred. 


\section{Conclusion}

An oceanographic campaign was performed on July 30, 2002 to study the shape and dilution of the S. Jacinto outfall plume using Isurus AUV.

Our results demonstrate that AUVs can provide high-quality measurements of physical (and probably optical) properties of effluent plumes in a quite effective manner. An efficient sampling strategy, enabling improvements in terms of resolution of time and space scales and undersampling, demonstrated that effluent plumes can be clearly traced using naturally-occurring tracers in the wastewater.

In order to reduce the uncertainty about plume location and to concentrate the vehicle mission only in the hydrodynamic mixing zone, outputs of a near-field prediction model, based on in situ measurements of current speed and direction and density stratification obtained in real-time, were used to specify the AUV mission.

A built-in application adaptively specified the AUV monitoring field transects according to the environment conditions, in real-time, taking into account the outputs of the model and the vehicle navigation requirements.

A data processing system was created, applying the Least Squares Collocation Method (LSCM) technique, in order to map effectively the dispersion of the effluent using the AUV data. LSCM results for salinity enable the effluent plume to be identified unambiguously and its dispersion downstream to be observed. The effluent plume appeared as a region of lower salinity compared to surrounding ocean waters at the same depth, rising to the water surface due to the relatively weak ambient stratification and relatively weak low currents.

Dilution was estimated using temperature-salinity, by means of a (TS-) diagram. The analysis demonstrated that effluent dilutions were at least 30:1 in this study. Dilutions estimated with the TS - method represent lower bounds of dilution, specially for surfacing plumes.

If artificial tracers had been used, better estimates of dilution would certainly have been obtained. However, since the present monitoring methodology is considerably less expensive and more practical for routine monitoring (not forgetting the negative impacts of releasing fluorescent dyes or other contaminant components in the effluent) further developments with the present system will certainly be justifiable.

Spectral fluorescence methods provide some promise for observing potentially-unique characteristics of effluent plumes (Petrenko et al., 1997). In the near future it would be interesting to Isurus AUV to test the potential of fluorescence measurements as a noninvasive, real-time technique to detect sewage fields in the coastal environment. AUVs also appear to be quite promising for studying the patchiness problem, in spite of several limitations that must be overcome in the future, such as predicting variability over broad time and space scales.

\section{References}

Alt, C.V.; Allen, B.; Austin, T. \& Stokey, R. (1994). Remote Environmental Measuring Units, Proceedings of the Autonomous Underwater Vehicles '94 Conference, July 1994.

Carvalho, J.L.B.; Roberts, P.J.W. \& Roldão, J. (2002). Field Observations of the Ipanema Beach Outfall, Journal of Hydraulic Engineering, Vol. 128, No. 2, pp. 151-160. 
Faisst, W.K.; McDonald, R.M.; Noon, T. \& Marsh, G. (1990). Iona Outfall, Plume Characterization Study, Proceedings 1990 National Conference on Hydraulic Engineering, ASCE, July 30 - August 3, 1990.

Fischer, H.B.; List, J.E.; Koh, R.C.Y.; Imberger, J. \& Brooks, N.H. (1979). Mixing in Inland and Coastal Waters, Academic Press.

Fletcher, B. (2001). Chemical Plume Mapping with an Autonomous Underwater Vehicle, Proceedings of MTS/IEEE International Conference Oceans 2001, Biloxi, Hawaii, USA, November 5-8, 2001, pp. 508-512.

Jones, B.H.; Barnett, A. \& Robertson, G.L. (2001). Towed Mapping of the Effluent Plume from a Coastal Ocean Outfall, Proceedings of MTS/IEEE International Conference Oceans 2001, MTS 0-933957-29-7, Biloxi, Hawaii, USA, November 5-8, 2001, pp. 1985-1989.

Matos, A.; Cruz, N.; Martins, A. \& Pereira, F. L. (1999). Development and Implementation of a Low-Cost LBL Navigation System for an AUV, Proceedings of the MTS/IEEE Oceans'99 Conference.

Matos, A.; Cruz, N. \& Pereira, F.L. (2003). Post Mission Trajectory Smoothing for the Isurus AUV, Proceedings of Oceans 2003 Marine Technology and Ocean Science Conference, September, 2003.

Millero, F.J.; Chen, C.T.; Bradshaw, A. \& Schleicher K. (1980). A New High Pressure Equation of State for Seawater, Deep-Sea Research 27A, pp. 255-264.

Petrenko, A.A.; Jones, B.H.; Dickey, T.D.; LeHaitre, M. \& Moore, C. (1997). Effects of a Sewage Plume on the Biology, Optical Characteristics, and Particle Size Distributions of Coastal Waters. Journal of Geophysical Research, Vol. 102, No. C11, pp. 25061-25071.

Petrenko, A.A.; Jones, B.H. \& Dickey, T.D. (1998). Shape and Initial Dilution of Sand Island, Hawaii Sewage Plume, Journal of Hydraulic Engineering, Vol. 124, No. 6, pp. 565-571.

Ramos, P. (2005). Advanced Mathematical Modeling for Outfall Plume Tracking and Management using Autonomous Underwater Vehicles based Systems, PhD Thesis, Faculty of Engineer of University of Porto, March 2005.

Roberts, P.J.W.; Snyder, W. \& Baumgartner, D. (1989). Ocean Outfalls, Journal of Hydraulic Engineering, Vol. 115, No. 1, pp. 1-70.

Roberts, P.J.W. \& Wilson, D. (1990). Field and Model Studies of Ocean Outfalls, Hydraulic Engineering Proceedings, 1990 National Conference, ASCE, H. Chang, New York, San Diego, July 30 - August 3, 1990.

Roberts, P.J.W. (1996). Sea Outfalls, Environmental Hydraulics, V. P. Singh and W. H. Hager, Kluwer Academic Press, pp. 63-110.

Roberts, P.J.W.; Hunt, C.D. \& Mickelson, M.J. (2002). Field and Model Studies of the Boston Outfall, Proceedings of the 2nd International Conference on Marine Waste Water Discharges, Istanbul, Turkey, September 16-21, 2002.

Robinson, A.R.; Bellingham, J.G.; Chryssostomidis, C.; Dickey, T.D.; Levine, E.; Petrikalakis, N.; Porter, D.L.; Rothschild, B.J.; Schmidt, H.; Sherman, K.; Holliday, D.V. \& Atwood, D.K. (1999). Real-Time Forecasting of the Multidisciplinary Coastal Ocean with the Littoral Ocean Observing and Predicting System (LOOPS), Proceedings of the Third Conference on Coastal Atmospheric and Oceanic Prediction Processes, American Meteorological Society, New Orleans, LA. 
Washburn, L.; Jones, B.H.; Bratkovich, A.; Dickey, T.D. \& Chen, M. (1992). Mixing, Dispersion, and Resuspension in Vicinity of Ocean Wastewater Plume, Journal of Hydraulic Engineering, Vol. 118, No. 1, pp. 38-58.

Wu, Y.; Washburn, L. \& Jones, B.H. (1994). Buoyant Plume Dispersion in a Coastal Environment: Evolving Plume Structure and Dynamics, Continental Shelf Research, Vol. 14, No. 9, pp. 1001-1023.

Yu, X.; Dickey, T.D.; Bellingham, J.G.; Manov, D. \& Streitlien, K. (1994). The Application of Autonomous Underwater Vehicles for Interdisciplinary Measurements in Massachusetts and Cape Cod Bayes, Continental Shelf Research, Vol. 22, No. 15, pp. 2225-2245.

Zhang, X.; Liu, X.; Song, K. \& Lu, M. (2001). Least-Squares Collocation Meshless Method, Int. Journal for Numerical Methods in Engineering, Vol. 51, pp. 1089-1100. 


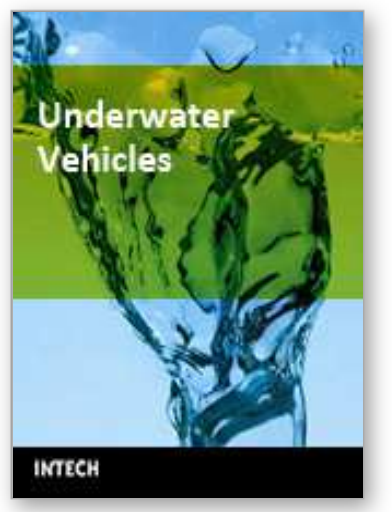

\author{
Underwater Vehicles \\ Edited by Alexander V. Inzartsev
}

ISBN 978-953-7619-49-7

Hard cover, 582 pages

Publisher InTech

Published online 01, January, 2009

Published in print edition January, 2009

For the latest twenty to thirty years, a significant number of AUVs has been created for the solving of wide spectrum of scientific and applied tasks of ocean development and research. For the short time period the AUVs have shown the efficiency at performance of complex search and inspection works and opened a number of new important applications. Initially the information about AUVs had mainly review-advertising character but now more attention is paid to practical achievements, problems and systems technologies. AUVs are losing their prototype status and have become a fully operational, reliable and effective tool and modern multi-purpose AUVs represent the new class of underwater robotic objects with inherent tasks and practical applications, particular features of technology, systems structure and functional properties.

\title{
How to reference
}

In order to correctly reference this scholarly work, feel free to copy and paste the following:

Patrícia Ramos, and Mário V. Neves (2009). Environmental Impact Assessment and Management of Sewage Outfall Discharges Using AUV'S, Underwater Vehicles, Alexander V. Inzartsev (Ed.), ISBN: 978-953-7619-497, InTech, Available from:

http://www.intechopen.com/books/underwater_vehicles/environmental_impact_assessment_and_management _of_sewage_outfall_discharges_using_auvs

\section{INTECH}

open science | open minds

\author{
InTech Europe \\ University Campus STeP Ri \\ Slavka Krautzeka 83/A \\ 51000 Rijeka, Croatia \\ Phone: +385 (51) 770447 \\ Fax: +385 (51) 686166 \\ www.intechopen.com
}

\author{
InTech China \\ Unit 405, Office Block, Hotel Equatorial Shanghai \\ No.65, Yan An Road (West), Shanghai, 200040, China \\ 中国上海市延安西路65号上海国际贵都大饭店办公楼 405 单元 \\ Phone: +86-21-62489820 \\ Fax: $+86-21-62489821$
}


(C) 2009 The Author(s). Licensee IntechOpen. This chapter is distributed under the terms of the Creative Commons Attribution-NonCommercialShareAlike-3.0 License, which permits use, distribution and reproduction for non-commercial purposes, provided the original is properly cited and derivative works building on this content are distributed under the same license. 